\title{
Erratum to: Group VIII Base Metal Nanocatalysts with Encapsulated Structures as an Area of Green Chemistry
}

\author{
Yu. H. Budnikova* \\ Arbuzov Institute of Organic and Physical Chemistry, Kazan Scientific Center, Russian Academy of Sciences, Kazan, Russia \\ *e-mail: yulia@iopc.ru \\ Submitted November 20, 2018; accepted November 20, 2018
}

DOI: $10.1134 / \mathrm{S} 096554411815001 \mathrm{X}$

The author's name should read Yu. H. Budnikova.

The original article can be found online at https://doi.org/10.1134/S096554411714002X. 